Article

\title{
Planning with Citizens: Implementation of an e-Planning Platform and Analysis of Research Needs
}

\author{
Stefan Steiniger ${ }^{1, *}$, M. Ebrahim Poorazizi ${ }^{2}$ and Andrew J. S. Hunter ${ }^{2,3}$ \\ ${ }^{1}$ Centro de Desarrollo Urbano Sustentable (CEDEUS), Departamento de Ingeniería Transporte y Logística, Pontificia \\ Universidad Católica de Chile, 4860 Santiago de Chile, Chile; E-Mail: ssteiniger@uc.cl \\ 2 Department of Geomatics Engineering, University of Calgary, Calgary, 2500, Canada; E-Mails: mepooraz@ucalgary.ca \\ (M.E.P.); ahunter@ucalgary.ca (A.J.S.H.) \\ ${ }^{3}$ McKenzie and Co Consultants Ltd., PO Box 259309, Auckland, New Zealand \\ * Corresponding author
}

Submitted: 29 February 2016 | Accepted: 1 June 2016 | Published: 20 June 2016

\begin{abstract}
Citizen participation should be an essential part of an urban planning process if the needs of the local population are to be addressed. Citizen participation should also improve acceptance of private construction projects by residents that live in or near such development. A complementary form of citizen participation to public planning meetings is to permit citizen engagement via Web 2.0 technologies, which also has the potential to get citizens involved that are usually difficult to reach. We aim to build a social, i.e. participatory, planning platform that allows technology savvy citizens to inform themselves of future and ongoing development projects and to also discuss them online. In this work we discuss the functional needs and context-of-use constraints of such an e-planning platform. A conceptual model of the technical architecture is outlined and a prototype implementation is presented. This prototype is built on free and open source software components, including a social network, to enable platform adoption in other locations. Finally, we discuss the research needs that are to be addressed if the development of participatory e-planning platforms should advance.
\end{abstract}

\section{Keywords}

design criteria; e-planning platform; open-source; participatory planning; PPGIS, social networks

\section{Issue}

This article is part of the issue "Volunteered Geographic Information and the City", edited by Andrew Hudson-Smith (University College London, UK), Choon-Piew Pow (National University of Singapore, Singapore), Jin-Kyu Jung (University of Washington, USA) and Wen Lin (Newcastle University, UK).

(C) 2016 by the authors; licensee Cogitatio (Lisbon, Portugal). This article is licensed under a Creative Commons Attribution 4.0 International License (CC BY).

\section{Introduction}

The advent of social networks, such as Facebook.com, Google+, and renren.com, and the emergence of communication applications for mobile phones, such as WhatsApp, have changed the way people communicate, particularly in countries with high Internet uptake (Ellison, Steinfield, \& Lampe, 2007; Pew Research Center, 2011). Likewise these communication tools have the potential to shape (urban) planning now and in the near future. In particular the requirement for public participation in planning processes could benefit from the engagement of people via social networks (Donders, Hartmann, \& Kokx, 2014; J. S. Evans-Cowley, 2010; Mandarano, Meenar, \& Steins, 2010; Staffans, Rantanen, \& Nummi, 2010). Interesting to note, on the one hand, is that researchers in Participatory GIS (PGIS) have for some time developed and explored webbased approaches to public participation (Bugs, Granell, Fonts, Huerta, \& Painho, 2010; Butt \& Li, 2012; Kingston, Carver, Evans, \& Turton, 2000; Rinner, Keßler, \& Andrulis, 2008). However, agencies that want to (or are legislated to) collect and consider public opinion as part of their decision making process have 
rarely adopted, let alone implemented, these participatory web-based GIS-probably due to the investments that must be made (Foth, Klaebe, \& Hearn, 2008; Hunter et al., 2012; Mandarano et al., 2010).

On the other hand, cities have lately recognized the possibilities that web-based feedback tools offer; particularly with respect to safe, clean cities as demonstrated by the adoption of platforms such as the international fixmystreet.org, the German "Maerker" (maerker.brandenburg.de) or the Chilean vecinosconectados.cl. However, only a small proportion of agencies and planning departments have explored possibilities that open up when using social networks for participation in planning activities (J. Evans-Cowley \& Hollander, 2010; J. S. Evans-Cowley, 2010; Riggs, Chavan, \& Steins, 2015). This is curious given the experience that political activists have had, who have adopted social networks to promote their cause, or that police have had, using social networks to aid crime investigation (Diehl, 2011). Probably the most widely adopted platforms for citizen-agency Web 2.0 engagement with a spatial/mapbased focus have been Ushahidi.com, a participatory crisis information platform, fixmystreet.com, and shareabouts.org for street safety reporting and bikeparking allocation. We add to this list the more recent North American MindMixer platform which allows to discuss planning issues with citizens. Communitymatters.org (Horose, 2014) offers a fairly comprehensive list of web tools for online public engagement.

So while there exist (i) webpages to inform people about planning activities, (ii) platforms for citizen issue/problem reporting, (iii) general social networks that allow neighbours to discuss and organize themselves, and (iv) at least one platform that focuses on asking citizens on planning issues (with questions posed by the city government); there does not exist a platform that integrates these different functionalities. Furthermore, there does not seem to exist a (planning support) platform, which permits to present and evaluate different planning scenarios, that was designed with a focus on the citizen as user, as opposed to the planning expert.

Our work on the PlanYourPlace (PYP) project aims to address the lack of such integrated participatory planning platforms, in short, e-planning platforms. Our primary use case aims to implement an e-planning platform that aids the development of community plans within and surrounding the City of Calgary, Canada. In our development scenario, the web-based platform should inform and educate community members about urban development options, and support their participation in the planning process.

Building on earlier work (Steiniger, Poorazizi, BlissTaylor, Mohammadi, \& Hunter, 2012) we evaluate which functionality an e-planning platform should provide and discuss general platform design considerations. We then present a technical architecture and a prototype platform that integrates the social network software Elgg. Finally, we discuss research topics that need to be addressed to move the development of participatory planning platforms forward.

\section{Possible Activities of the e-Planning Platform User}

For the development of an e-planning platform we advocate the position that it is preferable that the platform design focuses on social and collaborative aspects as adopted in a grass-roots planning approach, rather than an agency-centred perspective that focuses on controlled top-down information flows. Given this perspective, and the objective of decentralized communication, the choice of a social network-based approach for the underlying software architecture is a logical step. However, the use of social networks for participatory planning requires adaptation of social networking software. Whereas social networks provide functions for informing others, and for commenting and voting on content (e.g. articles, comments and images), they do not offer out-of-the-box planning-support functions, such as map-like display of development plans, or evaluation tools for different development scenarios, which brings us to the question: "What functionality is useful for future e-planning platform users?" To answer this question, we undertook an analysis of the planning and participatory GIS literature as well as existing online tools to establish a list of activities that support participation in planning, and functions that would enhance participation. The results of the literature review are documented in detail in Hunter et al. (2012) and summarized here.

When considering Smyth's ladder of e-participation (Smyth, 2001), which is somewhat similar to participation ladders of Arnstein's (1969), Kakabadse, Kakabadse and Kouzmin (2003), and organizations such as the International Association for Public Participation (n.d.), the lowest level of participation, online service delivery, is to inform the citizen (Figure 1). For planning this can take the form of plans, maps, documents, images, etc. However, as Talen (2000) and Drummond and French (2008) note, information should not flow in one direction only-from planning departments to citizens-but both ways to allow citizens to express their desires for their community. Providing community residents the ability to discuss planning projects with city planners, and with others from their community, elevates participation to the second rung of Smyth's eparticipation ladder: online discussion. Such functionality was proposed by Guhathakurta (1999) and Drummond and French (2008), among others, and was implemented in participatory GIS platforms by several groups (Hall, Chipeniuk, Feick, Leahy, \& Deparday, 2010; Rinner et al., 2008; Staffans et al., 2010; J. Zhao \& Coleman, 2006) and forms also the base of the MindMixer platform that is used by several North American cities.

The next step on the ladder of $e$-participation adds online survey capabilities that allow users to rank (e.g. 
sorting alternatives), rate (e.g. a 1-5 star rating scale as for products on Amazon.com), or vote (e.g. like or dislike) on alternative planning options (Seltzer \& Mahmoudi, 2013). Carver, Evans, Kingston and Turton (2001) and Voss et al. (2004), for instance, implemented participatory GIS applications that provided ranking functionality. Similarly, tools such as OpenPlans's ShareAbouts and the Akora citizen reporting platform (VecinosConectados, n.d.) have been developed and are used to determine bike-parking stations using a participatory approach.

The three activities outlined so far (1) providing information (i.e. content), (2) allowing discussions, and (3) enabling ranking, rating, and voting on content, progressively improve citizen participation for planning. We deem the corresponding platform functions to be required for any online participatory platform, and note that these capabilities are commonly found in social networks such as Facebook and Google+. Research prototypes of participatory online GIS implemented functions (1) and (2) as well (Butt \& Li, 2012; Carver et al., 2001; Voss et al., 2004).

The ultimate level of $e$-participation, as defined by Smyth (2001) is online decision support systems. This level of citizen participation in planning can be achieved with functionality that cannot be found in social networks. For instance Peng (2001) and Drummond and French (2008) proposed tools for the evaluation of planning alternatives. Such evaluations of planning proposals could be performed by calculation of indices that describe effects of a proposed planning change on demographics, transit use, resource and energy consumption, or even fiscal impacts. Hunter et al. (2012) give examples of decision support and evaluation models to be considered for the PlanYourPlace project-and have implemented models to calculate accessibility scores and crime indices for Calgary, Canada. The web-based portal of the Australian Urban Research Infrastructure Network (AURIN) has recently seen the addition of such online evaluation and decision support tools (Sinnott et al., 2015). However, these AURIN tools, such as the online What-If and EIAT, are primarily to be used by researchers and planning professionals, and only secondary have a focus on citizens as users (Pettit et al., 2013; Sinnott et al., 2015).
A higher level of e-participation in planning can also be achieved by developing tools that allow people to modify plans, or sketch completely new alternatives (Drummond \& French, 2008; Peng, 2001). To encourage discussion about these proposals, the e-planning system requires that these alternative (new) plans be shared with city planners and other citizens.

The provision of development plans in the form of two-dimensional (2D) map-like representations can be considered part of the "information provision" functions. However, a community resident's experience of "what things may look like" is likely to be greatly improved when three-dimensional (3D) views and animations are presented (Pettit, Raymond, Bryan, \& Lewis, 2011; Sheppard \& Cizek, 2009). Consequently, 3D views may help reach decisions for or against a project faster, and may help to select between different planning alternatives. For example, virtual-globe technology with 3D visualization of the proposed built environment for participatory planning is presented in $\mathrm{Wu}, \mathrm{He}$ and Gong (2010).

We summarize these 8 activities in Figure 2 . In this figure, we have also introduced two additional functional categories: "Manage" and "Learn". "Manage" refers to a set of necessary user and document management tools, whereas "Learn" refers to a set of education tools. Why these two activities are added will be outlined next.

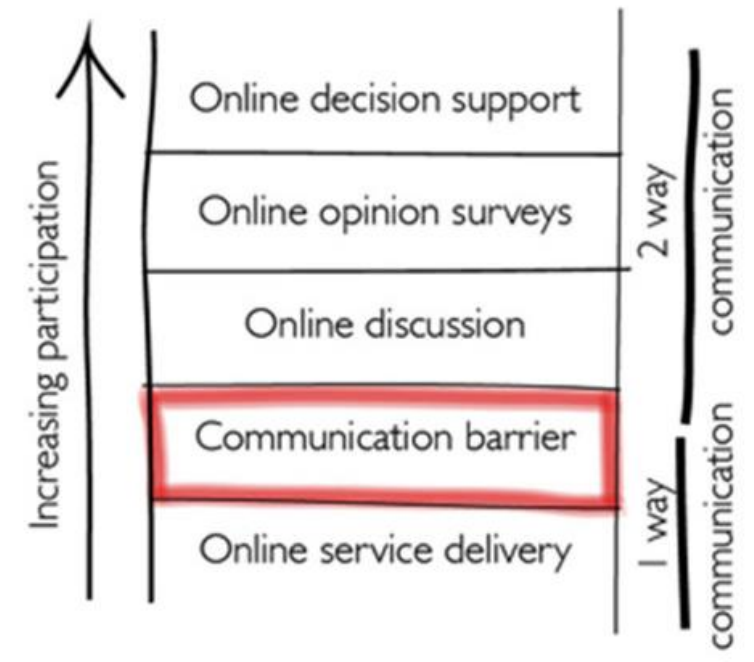

Figure 1. Smyth's (2001) ladder of e-participation.

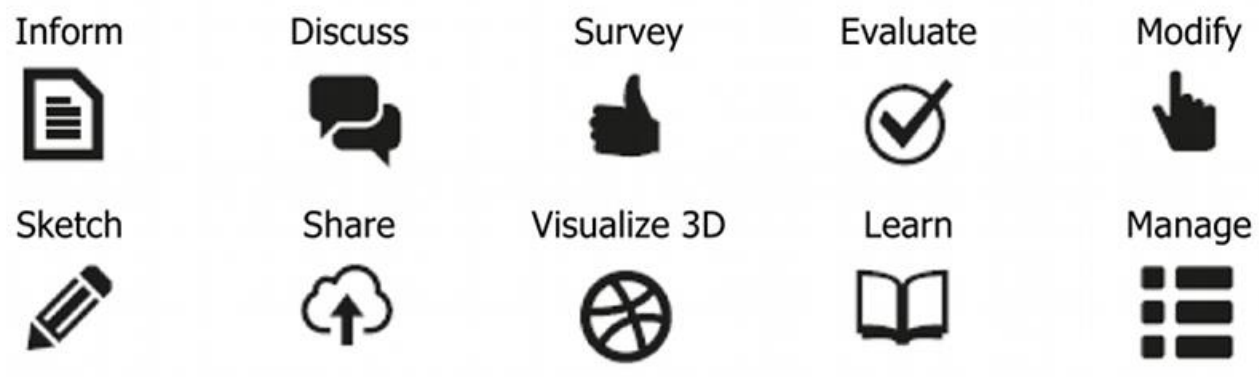

Figure 2. Proposed planning support functionality for $e$-planning platforms. 


\section{Platform Design Considerations}

When designing an e-planning platform, developers must consider more than simply (i) the activities that a user should preform, i.e. functions that the planning platform offers (as outlined above). One should also consider (ii) the user, and (iii) the context of use (Rubin \& Chisnell, 2008). Further constraints for platform design originate from the geographic data and planning related documents that are to be provided. The following sections discuss the types of constraints that have emerged from our analysis, leading to human and technical design factors that should be taken into consideration.

\subsection{The Platform User}

As Rubin and Chisnell (2008) have noted, for a usercentred design (UCD) approach it is important that designers have a close look at the cohort of future platform users. We consider three general groups of users for the e-planning platform: citizens, city planners, and decision makers (Hunter et al., 2012). City planners shall use the platform to inform citizens about on-going planning projects and proposals, and to obtain feedback on these. Decision makers are able to gain (almost) immediate reactions on proposals, and will have the opportunity to discuss and argue for or against planning projects. The biggest user group consists of citizens, i.e. community members, who will use the website to inform themselves, discuss proposals with others, and express their opinion by voting or commenting on proposals. Given these three user groups, the set of e-planning-specific questions that should guide the platform design are:

User Age: What are the different age groups? High school students may already know how to use the platforms social network functions-e.g., creating a profile; adding content (images, movies, etc.); commenting on messages; and discussing with others-from their own experience with social networks. Whereas persons who have never used a social network before may be overwhelmed by the options, and they require some assistance to learn the functionality.

User Computer Literacy: What is the computer literacy of the users? Do people use a computer daily, or just occasionally? Hence, do they feel comfortable with computer use? If not, then they may need an introduction to the platform, which can be in the form of training (e.g. held in a community centre), a user manual, or an online demonstration. The provision of customized dashboards for different levels of user literacy is a further support option, as pointed out by Pettit et al. (2012).

User Planning Literacy: What do citizens know about planning processes? If they have participated in Charrettes (Lennertz, Lutzenhiser, \& Failor, 2008) and community planning events before, then they may understand how the information they provide to city planners will be used. In that case, they may also understand various planning terminology, and the steps taken to move through a planning process. If not, the system needs to educate the users about these issues.

Disabled Users: How can we ensure that disabled people can access the information and participate in discussions? What are the planning issues that may interest them in particular?

User Privacy: How can we ensure anonymity and privacy? Both are important, for instance, when a user may have an opposing opinion that they wish to contribute to a discussion, but choose not to as it may bring them unwanted attention (Gutmann \& Stern, 2007), or even real life attack.

User Identity: How can we ensure that votes and comments stem from a real person? i.e. how can we avoid having one person or a group of persons use several identities to sway votes and discussions?

Related to the questions about user literacy are problems identified by Nivala, Brewster and Sarjakoski (2008) and Newmann et al. (2010). Nivala et al. (2008) discovered in their usability study that while users of web maps had problems understanding, and using, zooming and panning functions - they also had problems understanding search operations, and the results produced by their search. Newman et al. (2010) found similar problems related to web page and map navigation, the understanding of map icons, and the use of seemingly simple functions such as user registration on their website.

As a consequence of the questions, activities, and issues presented above, the platform design should consider several points: (i) design of an interface that is accessible for different age groups, novice computer users, and disabled people; (ii) allow users to contribute anonymously; and (iii) ensure that each contributor has a unique identity. (iv) Finally, it is necessary to provide educational materials (online and for download) that allow users to explore and learn the platforms functionality, to learn about planning processes and planning law, and promote knowledge about sustainability criteria necessary for effective planning scenario evaluation. Points (ii) and (iii) are part of the "manage" activity in Figure (2), whereas the educational tools correspond to the "learn" activity of the same figure.

\subsection{Context of Use and Data Access}

While the reflections in the previous section influence functional and content aspects of platform design, the "use context" of the participatory planning platform strongly influences the technical aspects, i.e. the technical architecture. Important design considerations with respect to the context of use are:

Accessibility: Users need to be able to access the 
platform from home (citizen), from work (city planner and decision maker), or even from somewhere on the street with a mobile device. Hence, the platform should run on different types of devices without the need to download additional software. A web-browser solution is therefore a logical choice.

Management: The content, i.e. documents, plans, images, etc., for each development project may be managed by different entities, i.e. the responsible planning agency, be it a local government, or a community group. In addition, the data that are displayed by the map interface will likely only be partially hosted within the e-planning platform, and additional data will be "delivered" directly by data custodians (e.g., a city department), similar as for the AURIN platform (Barton, Goldie, \& Pettit, 2015). Consequently, the technical architecture should utilize a "Data as a Service" approach that could be based on Open Geospatial Consortium (OGC) standards (Percivall, 2010; P. Zhao, Yu, $\&$ Di, 2007), for example.

Flexibility: For the evaluation of proposed plans, via various assessment models, it is beneficial to "plugin" models rather than to integrate them - as for instance realized with the Online What-If model of the AURIN platform (Pettit et al., 2013). Hence, the architecture should be designed in such a way that models are treated as, and accessed through a web service, such as the OGC Web Processing Service (Schut, 2007). In particular, one can treat the models as "Software as a Service" (Granell, Díaz, \& Gould, 2010). This allows addition of further assessment models over timewithout changes to the system architecture-and ensures that the integration of improvements to the models does not affect other architectural components, nor cause website downtimes. Using a service-based architecture will also enable installation of a particular model on different computers so that distributed processing can be employed during high-demand times.

Security: In social networks people usually have a profile that contains personal information. Such information should not be accessible by others, unless approved by the profile owner. Hence, an authentication model (i.e. authentication manager) that controls access to data and user information is a critical component of the architecture.

Licencing: Licenses for software and geographic data need to be considered when building the system. For instance Carver et al. report on efforts that were required to license mapping data from the British Ordnance Survey for their participatory GIS, at a time when free map services such as OpenStreetMap did not exist (Carver et al., 2001). License restrictions may have two different types of effects for e-planning platforms: First, licences for data may prohibit the presentation of certain types of data/information to certain user groups, e.g., a decision authority may see more information than a community leader, or vice versa. In addi- tion, data licenses may restrict access based on where the platform user resides. Second, licenses and the related pricing for software can restrict the ability to setup and customize the platform. Hence, budgetary limits as well as restricted access to under-the-hood software functions can hinder the adoption of the platform by communities and cities. For this reason the project strives to employ a free and open source software strategy (Steiniger \& Bocher, 2009).

In summary, the five points above require that the participatory platform architecture: (i) be web-based, (ii) be (OGC service) standard-based for data and assessment model access, and (iii) has a software module that manages user access to ensure data security and conformance with data licenses.

An additional issue that falls between the UCD categories of user, user actions, and context is that of ownership over the data created in the $e$-planning platform by the users (see Hunter et al., 2012). Content that can be created includes text comments, votes, photos that may be uploaded, etc. Depending on what is decided by the platform provider, i.e. all or some created data will be owned by the platform provider or, alternatively, will be made accessible under an open data license, ownership may affect platform functionality (data access options) as well as platform architecture (e.g. service types used).

\section{Detailed e-Planning Platform Functionality}

Having defined the activities that $e$-planning platform users will likely perform, and having outlined several user-based and context-based design constraints, we have derived a detailed list of recommended platform functionality-shown in Table 1. This list contains 10 different groups of functions, whereby including the $e$ planning activities of Figure 2: (1) management tools, (2) visualization tool, (3) 3D visualization tools, (4) information tools, (5) discussion tools, (6) survey tools, (7) evaluation tools, (8) sketching tools, (9) sharing tool, and (10) learning tools.

We then compared this list with standard functionality offered by social networking software, specifically the social network software Elgg (Costello, 2012). One can see from Table 1 that a large number of the recommended functions are readily available in this social network. As Sani and Rinner (2011) noted in their comparison of Web 2.0 and PGIS functions, the existing functions are S-L-A-T-E-S functions (McAfee, 2006), i.e. functions that permit Searching, Linking, Authoring, Tagging, Extension/recommending, and Signalling. "Authoring" functions enable neighbours to comment on a development project, and are necessary for city planners and community members to write project news and articles. "Linking" to further, perhaps more detailed, information is possible with the same authoring tools. "Signalling", in an e-planning sense, relates to 
Table 1. Detailed functionality recommended for an e-planning platform.

\begin{tabular}{|c|c|c|}
\hline Tool Group & e-planning Functionality & Elgg Social-Network Functionality \\
\hline \multirow{5}{*}{ Manage } & User authentication & $\bullet$ \\
\hline & User social network profile & $\bullet$ \\
\hline & User anonymous login and commenting & \\
\hline & Create development project & \\
\hline & Subscribe to development project & O \\
\hline \multirow[t]{3}{*}{ Visualize 2D } & Display topographic map with communities & \\
\hline & Display planning projects & \\
\hline & Display reported issues & \\
\hline Visualize 3D & Dynamic 3D explorer & \\
\hline \multirow[t]{8}{*}{ Inform } & Search information, projects, and documents & $\bullet$ \\
\hline & Informing about new projects in area of interest & \\
\hline & Posting project news and articles & $\bullet$ \\
\hline & Uploading documents (text, video, images, etc.) & $\bullet$ \\
\hline & Reporting issues to the community & \\
\hline & Informing about latest project news & o \\
\hline & Informing about hottest discussions & \\
\hline & Creating events & O \\
\hline \multirow[t]{4}{*}{ Discuss } & Comment on issues and documents & $\bullet$ \\
\hline & Messaging to other platform users & $\bullet$ \\
\hline & Live-chat with others & $\bullet$ \\
\hline & Forum / group discussions & $\bullet$ \\
\hline \multirow[t]{4}{*}{ Survey } & Rating (1-5 stars) & o \\
\hline & Like \& Dislike & $\bullet$ \\
\hline & Preference survey tool & \\
\hline & Ranking alternatives & \\
\hline Evaluate & $\begin{array}{l}\text { Provide functions for indicator calculation via assessment } \\
\text { models for planning scenarios. }\end{array}$ & \\
\hline \multirow[t]{2}{*}{ Sketch } & Modify development plans & \\
\hline & Create new plans & \\
\hline \multirow[t]{2}{*}{ Share } & Sharing documents (text, images, videos etc.) & $\bullet$ \\
\hline & Sharing modified and created plans & \\
\hline Learn & $\begin{array}{l}\text { Provide education tools on: (i) platform use, (ii) planning } \\
\text { processes, (iii) sustainability, and (iv) assessment tools. }\end{array}$ & \\
\hline
\end{tabular}

Note: • Elgg out of the box (i.e. standard) functionality; o functionality provided by an additional Elgg plugin/module.

functions that permit users to notify other users of new development projects or project-related content. Tools that enable citizens to report positive and negative comments about locations within their neighbourhood can be considered a form of geo-"tagging".

Hence, given the existence of these social network functions it appears to us at least that the best approach is to add e-planning functionality to a social network platform. From a developer's perspective, this will avoid re-inventing the wheel and save development effort. From a user's perspective, there is the added benefit that many e-planning platform users are likely to be social network users. Therefore they will be comfortable with using standard social network user interfaces and functionality-reducing the need for additional user introduction and training.

\section{Technical Architecture of an e-Planning Platform}

To develop an e-planning platform it is necessary to give some thought to the technical architecture that is required to offer all the functionality in Table 1 . We speak here of a technical architecture since different software modules, on perhaps different servers, need to work together. The architectural design needs to address in particular the context-of-use related constrains that we identified earlier: (1) users can have access from different locations; (2) data are stored in different locations; (3) data may be processed with different models maintained at different locations; and (4) user access rights and data security are addressed. Interestingly, all these constraints are well known from the Spatial Data Infrastructure (SDI) literature (GSDI, 2009; Percivall, 2010; Rajabifard \& Williamson, 2001). It is therefore beneficial to build on the implementation experiences and robust technical standards that are used for SDls when developing an e-planning platform architecture. An important set of standards for the implementation of SDIs was, and continues to be developed by the Open Geospatial Consortium (OGC). 
These standards allow transfer, manipulation, analysis, and display of geographic data. Building on those existing standards, we have developed a conceptual model of the technical architecture shown in Figure 3.

This conceptual representation distinguishes between four functional architectural components: First, a presentation layer that presents information to the user and that allows the user to interact with the platform via the user interface (UI)-e.g. by navigating the map, or pressing buttons. This layer has two base components: a social network UI and the map viewer UI. Second, an application layer that integrates the services that are offered to users and allows communication between users, e.g. allows chats and messaging, and use of services, e.g., trigger services and present results. In the application layer we account again for two different application components: one that handles social-network related functions, including also user management, and one that handles planning and mapping related functionality.

Third, a service layer that consists of the different types of (web) services that provide data search, data processing, data access and display functions. We suggest for example a (1) "view service" that generates map like images, a (2) data "download service", to retrieve data or subsets of data, (3) a "processing service" that will handle evaluation of development plans using predefined models, e.g. a walkability model or an environmental impact model, (4) + (5) two "discovery services", one for planning data and one for social network data, which allow searching of both data streams, and (6) a "social data mining service". The social data mining service(s) should analyse incoming data and user profiles to notify users of the hottest discussions, new project information, etc., and support platform administrators in evaluating survey data and user comments.

Finally, the fourth conceptual layer is the data layer. Its function is to store and deliver data needed for view, download, and processing services. One database will handle in particular the data from the social network, and another exclusively the mapping-related (GIS) data. The third data module, denoted simply "Data Service" in Figure 3, will connect to external data that are not stored as part of the platform, such as topographic data from mapping agencies or demographic data from statistic departments (e.g., base map data provided by web map servers such as a WMS or WMTS).

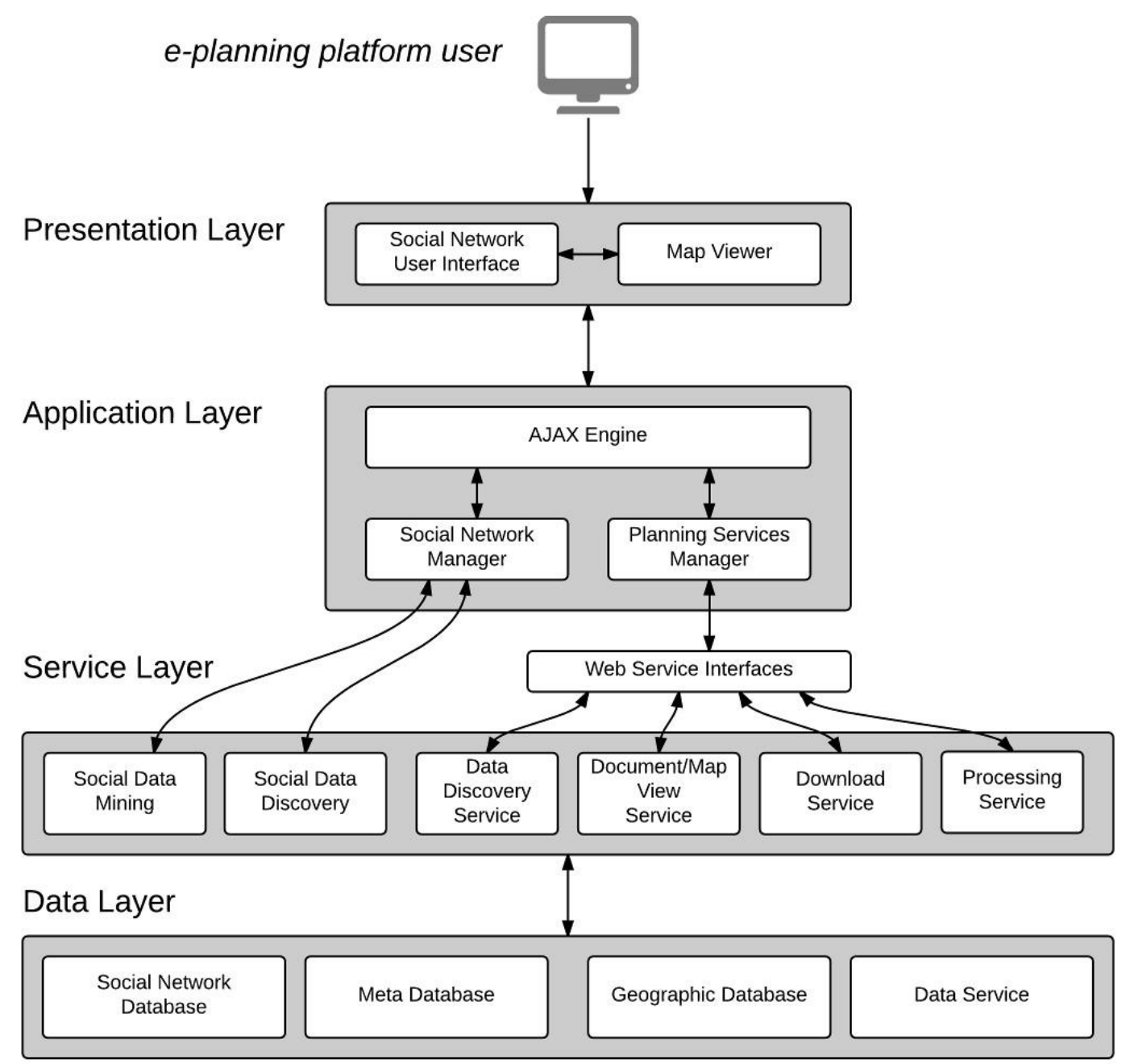

Figure 3. Conceptual four-tier architecture for an e-planning platform. 
A fourth module, the "Meta Database", contains a database that stores metadata needed to enable search functionality for external and internal web-services and data. The Meta Database is used by the two discovery service modules in the service layer.

As mentioned earlier, the ability to transfer planning data and evaluate plans using specified models via web-processing services should function within a standardized web-service environment-which is why we included a "web service interfaces" component in the diagram. Poorazizi, Steiniger, and Hunter (2015) outline in detail how existing web service standards, such as OGC's Web Feature Service (WFS) for vector data transfer, and OGC's Web Processing Service (WPS) for running evaluation models can be used (Percivall, 2010; P. Zhao et al., 2007). However, non-OGC standards for data and processing can be utilized as well. For instance the AURIN platform utilizes the GeoJSON standard that describes a fairly simple data schema for data web-services (Sinnott et al., 2015).

\section{PlanYourPlace, an e-Planning Platform Prototype}

The PlanYourPlace project was established to develop a rich web-based resource for community planning, education and collaboration. The prototype of that platform aimed at providing data and information to residents, planners and decision makers for a handful of neighbourhood communities in the City of Calgary, Canada. The implementation of the prototype is and was to be performed in a modular and iterative fashion. That is, after generation of a new or selection of an existing, suitable base platform the new e-planning functionality was added. We added new functionality based on internal priority and resource evaluationsimilar to the SCRUM software development approach (Schwaber \& Sutherland, 2011).

\subsection{Software Used}

The social-network Elgg (Costello, 2012) was chosen as the base platform following an evaluation of existing social-network software. Important evaluation criteria were: that the software be open source; has well-sized developer and user communities; is stable; allows extension of the platform using modules and plugin mechanisms; has a data access and security handling system; and, comes with a basic set of communication and document handling tools, e.g. SLATES functionalities. Limiting the selection of software to software that is distributed under free and open source licenses was done to ensure that we are able to customize the software components to any degree we deem necessary, and to be able to re-distribute it later without any restrictions to testing and improvement in future re- search work by us and others (Hunter et al., 2012).

To extend Elgg with e-planning functionality, and in particular, to add capabilities for the display, storage and management of spatial data, we first utilized OpenLayers and later Leaflet as the map viewer, and employed PostgreSQL/PostGIS as the spatial database (Steiniger \& Hunter, 2013). Elgg itself uses the database MySQL to store user-related data.

The software GeoServer was used to setup spatial data processing workflows as OGC Web Processing Services (WPS), which permit the evaluation of current urban infrastructure and urban development plans, for instance the evaluation of urban accessibility. Most of this software was installed on one server running on a LAMP (Linux-Apache-MySQL-PHP) configuration. However, a further server is employed to run evaluation models as remote web-services and to deliver customized community base-maps using the software TileMill and PHP TileServer. External data sources are also included via standard web protocols, such as base-maps from Google Maps and MapQuest, and location geocoding services from Google.

\section{2. e-Planning Functionality Implemented}

To test out the functionality implemented so far the reader is referred to the prototype at www.planyour place.ca/elgg. We note, however, that most of the tools are only accessible after registration (the reader may use "ijgiuser" with "ijgitest" for exploring the platform)-and that navigation may be slow due to limited resources of the hosting server. From the 10 different functionality groups shown in Figure 2, the prototype implements 6 functionality groups: tools to inform, discuss, survey, evaluate, share and manage content (see Figure 4). A particular survey tool that we developed is the MapYourPlace tool, which allows users to create map-based comments on what they like or don't like in their community (see Poorazizi et al., 2015). The first evaluation tool developed is WalkYourPlace. It evaluates accessibility and/or walkability of the user's neighbourhood based on the number of public services, parks, shopping, etc. within a given walk-time (see Steiniger, Poorazizi, \& Hunter, 2013). The tool also evaluates the level of crime within the same walk-time area to estimate a crime-index. We also implemented and evaluated approaches for the provision of interactive learning support tools for sustainability education (Bliss-Taylor, 2014). How to design a set of (interactive) learning tools, tools for scenario/plan modification, i.e. the sketching of completely new scenarios, and intuitive $3 \mathrm{D}$ visualization of planning scenarios needs to be researched further. As such, we will discuss related research needs below. 


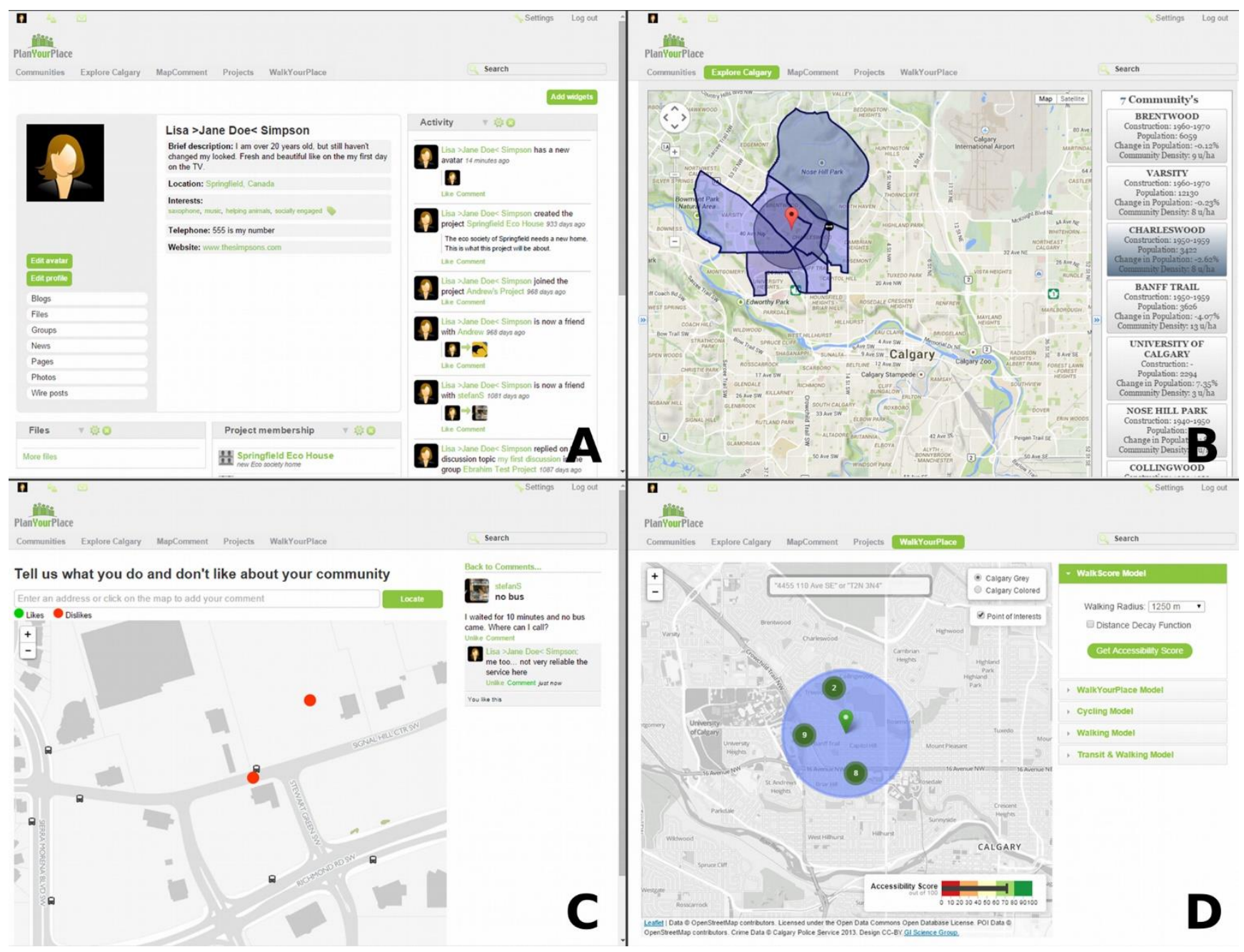

Figure 4. Screenshots of the e-planning platform prototype for PlanYourPlace.ca. Image A: user profile view; Image B: "Explore Calgary" a community information tool; Image C: "MapYourPlace" a community feedback tool; Image D: "WalkYourPlace" a tool to evaluate accessibility, here shown with www.walkscore.com concentric model with 1 mile walking radius.

\subsection{Fulfilled Development Constraints}

The current prototype covers most of the seven constraints that emerged from the platform's user profile and context-of-use. The three context-of-use constraints defined the basic architecture: First, the prototype platform is web-based so that information can be accessed from anywhere. Second, the prototype utilizes OGC Web service standards for data exchange (e.g. OGC WMS, OGC WMTS) and data processing (e.g. OGC WPS). Third, it has an access handler that can restrict and permit certain user groups to access data in the platform.

Looking at the four user induced constraints, the current prototype ensures that each user has a unique identity. Some prototype functions permit the submission of anonymous contributions so that people can speak freely. However, education material still needs to be developed. This is, as outlined above, an area of ongoing work (see Bliss-Taylor, 2014). Also the question of whether or not the design of the user-interface is user friendly and perceived as useful, across a range of diverse user groups, has yet to be answered. This requires the completion of a usability evaluation study in the future, perhaps in a similar fashion as the AURIN usability evaluation (Barton et al., 2015). For such a study the implementation and use in two or three realworld scenarios (i.e. communities and development projects) is necessary. However, performing and reporting on the usability study is not the focus of this paper, as our objective is to present the design criteria and a first prototype that embraces these design requirements. Or, as Rykiel (1996) formulates: the development of a model is one task, while validation of a model, in our case the platform, may be done by the research community.

\section{Discussion-Or What We Have Learned}

We gained three major insights during design and development of the e-planning platform. The first insight is that platform development should adhere to the principles of user-centred design (UCD). Following a 
UCD approach made us aware of the different types of user groups that the platform should serve, and the different contexts in which a user might interact with the platform. Applying a cyclic approach to developmententailing design, develop, evaluate (by users), and refine steps-as recommended by usability (Nielsen, 1993; Rubin \& Chisnell, 2008) and software development experts (Cohen, Lindvall, \& Costa, 2004; Laanti, Salo, \& Abrahamsson, 2011), should ensure that the platform is understandable to first-time users and can support citizen engagement. Within the domain of participatory (web) GIS, Haklay and Tobón (2003), Jankowski, Robischon, Nyerges, Ramsey and Tuthill (2006) and Rinner and Bird (2009) have also pointed out the advantages and need for UCD and usability evaluation.

Second, investigating functionality requirements for the e-planning platform made us aware that social networks possess a lot of the functionality that we believe a participatory e-planning platform should offer. In our case, the social networking software Elgg (Costello, 2012) provided functionality for communication among citizens, and between citizens and planners, and functions for sharing, commenting on, and voting for or against "content". Hence, when it comes to the implementation of an e-planning platform we would argue for the use of a social network as a base platform, instead of adding SLATE functions to (existing) mapping platforms. However, it has been pointed out that utilizing social platforms as a source of knowledge, such as Twitter, Facebook etc., will also require development of tools to filter relevant messages from uninformative messages (see Haworth \& Bruce, 2015), and to develop mechanisms that prevent that groups can sway discussions and votes (see above).

The third insight came when we studied the constraints related to platform-users and context-of-use. The constraints that we found were similar to requirements for implementation of an SDI. The need for distributed data storage, data processing, and security measures suggests that $e$-planning platforms can be seen as a specialized and extended version of an SDI. Thus it makes sense to build the participatory platform based on open standards (OGC, ISO, W3C) and principles that have been developed for SDIs (see GSDI, 2009; Percivall, 2010). Subsequently, the e-planning platform prototype for PlanYourPlace uses OGC standards and adopts SDI principles (for a more technical perspective see also Poorazizi et al., 2015).

However, related to the choice of OGC standards we like to add two comments: First, the AURIN architecture tries to avoid the use of OGC compliant internal components in favour of more recent and more flexible data access methods such as REST and GeoJSON (Tomko et al., 2012). Although this offers more flexibility, it requires additional customization to use and connect to a new particular data service-which is exactly what OGC standards try to avoid (see detailed explanations in Poorazizi et al., 2015). Second, it is apparent that Google Maps and ArcGIS are used by thousands without support for OGC standards, using proprietary protocols instead. However, avoiding OGC standards means that users have to stay within a particular software vendor "ecosystem" that have the tendency to "lock-in" the data into this system. The effect is that a service provider dependency is established. This usually involves that moving data out of the system can become very costly (with respect to time and money). It also comes at the risk that such service may at some day not be offered anymore after some business evaluation, like it happened with the Google Maps Engine (King, 2015).

\section{Research Needs for Participatory Planning Platforms}

Given our work on the platform design and the practical implementation we have also explored the limits of the knowledge available for building e-planning platforms. Hence, below we outline where we see what the research needs are, particularly from a technical perspective.

The prototype for an e-planning platform as presented is missing functionality that permits modification of existing infrastructure plans. It still needs to incorporate sketching of new development scenarios, and $3 \mathrm{D}$ visualisation of scenarios. Furthermore, prototypes for interactive educational support tools have been studied-but are not included, and we have "only" two indicators for scenario evaluation implemented. The reason for not having advanced further on these functionalities is a dearth of general knowledge on how to implement such fairly complex tools best. In the following we detail seven topics that we think require dedicated research if $e$-planning platforms should advance in a manner useful for citizens, planners and decision makers.

User Support tools (education): There is a need for the development of content, presentation concepts and support tools for the support/education component of $e$-planning platforms. Support should enable participation at high levels on the participation "ladder" (Arnstein, 1969), and provide help with the use of sustainable urban development strategies (Schwilch, Bachmann, \& de Graaff, 2012). There is little literature concerning potential sources of support for public participants. Numerous participation and/or decision making tools already exist to aid urban planning participants (Cinderby, 2010; Tippett, Handley, \& Ravetz, 2007). But, most of these are intended for use in inperson processes. These applications cannot address the need for support when public participants are gathering online. As Poplin (2012) asks "How can one create a pleasant virtual environment in which citizens learn about current situations?". 
The tool should consider all perspectives, providing information that would interest those with diverse perspectives. Qualitative and quantitative, short-term to long-term, small-scale and whole-system, political, social, economic, and environmental factors should all be considered. Support tool communication should focus on issues that are important to intended users, and work with their existing understanding of sustainability, urban planning, and related issues. In general, public understanding of sustainability varies in depth from the use of simple definition to avoid engaging with the concept, through appreciation of resource use implications, to recognition of the equity and justice issues involved (Reid \& Petocz, 2006; Reid, Petocz, \& Taylor, 2009). To compound the problem content must be written in a language that caters to the "average" citizen (if there is such a thing). Development of educational support tools also requires research that considers different user groups, interaction design, and instructional design (Sandars \& Lafferty, 2010).

User Interface Design/Visualization: For e-planning platform functions that allow users to report issues to the city (e.g. areas they like, where they feel unsafe, or a pot hole, etc.), the prototype offers a reporting user interface that is map based. That is users "simply" place a pushpin on a map and describe what they have encountered, or their concern, in a text box. This appears straightforward, but Nivala et al. (2008), Roth and Harrower (2008), and Newman et al. (2010) found that some users of web maps had difficulty navigating the map and did not understand, or misunderstood map symbols. This makes us question if a purely map-based approach is useful. An alternative to a map-based user interface is a text-based version, as commonly used in social network websites, and adopted by the German reporting platform Maerker.Brandenburg.de that lets citizens report street maintenance issues.

However, as Rubin and Chisnell (2008) have pointed out, the best approach is probably in the middle of the two different designs. Hence, user evaluation of each design (map-based vs. text-based) is needed to obtain directions towards a "most usable" user interface. This includes also the need for research on the usability of navigable 3D visualizations of planning scenarios, as pointed out by Sheppard and Cizek (2009). Connecting interface design and learning we suggest that only a simple interface, i.e. dashboard, with some very basic functionality is presented to the "rookie" user of the platform. After some time of using the platform, and perhaps after "graduating" from tutorials, more complex functions and tools with analysis and sketching functionality would extend the users' dashboard. This way one can probably avoid that the user gets overwhelmed after logging in for the first time.

Assessment Models and Metrics: e-planning platforms need to provide tools to evaluate existing infrastructure and planned developments based on eco- nomic, environmental or demographic indices. Several indices and models have been developed as components of planning support systems in the past. Hence, it will best to develop (simplified) interfaces that will connect to these tools instead of developing models from scratch (see Pettit et al., 2013). However, it is important to choose metrics that are understandable to, and resonate with community members so that users can make sound decisions. For instance, in the PlanYourPlace workshops "cost" was raised as an important and understandable metric (Hunter, Sandalack, Liang, Kattan, \& Shalaby, 2011). As a result such metrics, among others, should probably be featured. Research in this area is needed to identify metrics that citizens understand well and that account for individual perspectives, but also for societal long-term impacts.

Planning Scenario Tools: Sketching functions of $e$ planning platforms should allow (i) creation of markups and annotations to existing development plans, (ii) creation of new plans, and (iii) modification of proposed plans. Central questions for developing the sketching tools are: (1) How should the user be able to mark-up plans and how is this information attached to plans? (2) How and what objects of an existing plan/map can the user edit? (3) How should the sketching be done? For instance, is it better to adopt the approach of planning-like games such as SimCity/ Micropolis where the platform provides a set of objects (e.g. a house or a road segment) that can be added to a plan by drag \& drop, or is it better to allow free-form drawing, as one would with pen and paper?

An important component of the research and development on sketching is most likely object and object-context recognition. This is necessary, since free form sketching by the user requires the platform to recognize what the user wants to draw and, eventually, provide drawing support. The generation and utilization of ontologies together with Bayesian inference methods may yield a promising approach for such object and context recognition (Alvarado \& Davis, 2004; Lüscher, Weibel, \& Burghardt, 2009; Yin, Chang, \& Forbus, 2010).

Mining Tools: User will be able to vote (like/dislike), rate (5-star rating scale), rank, and comment on content. Here, the term "content" refers to images, development plans, other comments, news, etc. Mining tools are necessary to evaluate what preferences users have and summarize these in reports. These tools should be able to be used by community administrators or city planners. Hence, by users that may not have strong computer skills. Subsequently the interfaces of the evaluation functions should be simple and understandable as well. Research should address the development of methods to combine voting data, user profile and network data. These methods will allow to identify user groups with particular preferences and to identify trends in preferences. 
Mobile Tools: The wide spread use of smart phones brings new challenges but also a lot of opportunities to participatory planning (J. Evans-Cowley, 2012). On the one hand, an e-planning platform should allow users to access the planning information "in the field" so that a neighbour can explore right at the spot how a development proposal may look like and what it effects may be. Such possibility calls for augmented reality tools that can display planning scenarios (e.g. a new building) in virtual manner over existing terrain as demonstrated in Allen, Regenbrecht and Abbott (2011) and Oksman, Väätänen and Ylikauppila (2014). It also calls for place-based evaluation models and tools that take the current users positions, such as walkability or bikeability scores. On the other hand, mobile phones offer the opportunity for data collection (Bohøj, Borchorst, Bødker, Korn, \& Zander, 2011). For instance, the $e$ planning platform can profit from mobile photo uploads that present the current situation, or users can geo-tag their favourite or disliked places in the neighbourhood. The utility of these three uses (visualization, evaluation and data collection) of mobile tools will be in solving and identifying current and local problems. They will, however, be probably less useful when one considers long term, and citywide or regional planning.

Institutional Integration: Government at this point has little experience extracting innovative knowledge out of exchanges on social media sites. It is unclear to what extent the information that flows into government is governed, processed, used and how government acts on information that is created with and among their audience members in conversations on social media platforms. Online deliberation research needs to become more attendant to outcomes-not simply in terms of whether participants trusted the process, but in terms of the political efficacy of citizens and of policy outputs. As Bang \& Esmark (2009) suggest, new modes of governance have placed emphasis on the democratization of citizen input, but without outputs, no form of collective action, including talk, amounts to much. The political process does not stop when the talking stops. Online deliberation is not an alternative to political decision-making, but a means of enhancing it. In any representative democracy, deliberation by the public, stakeholders and decision makers is but one stage in the complex process of turning preferences into implementable policy. We know very little at the moment about how online deliberative talk turns into institutional decision making. How, technically, can e-planning content creation and deliberation be integrated into existing planning decision making processes. To this end, there is a need for the mapping of institutional process through which online deliberation must connect with to increase the efficacy of citizens (Coleman \& Moss, 2012).

Apart from these seven main research themes there are of course further research and development topics that address augmentation of platform capabilities, for instance the development of tools that allow to compare two or more planning scenarios vis-a-vis. However, our personal top-three priority list for future research consists of education support tools, the development of assessment models, and the work on planning scenario-sketching tools. Because the education tools and assessment tools are indispensable for platform adoption by citizens, and both can further the probability of platform use directly in public participation planning meetings to demonstrate things and invite people. Finally, the scenario sketching tools are useful to planners and citizens to explore different planning scenarios.

\section{Acknowledgments}

We thank Ehsan Mohammadi and Coral Bliss-Taylor for their work on the "Explore Calgary" tool and the educational support tool design, respectively. We are grateful for funding from the Canadian NEPTIS Foundation and GEOIDE (Grant TSII 202). Stefan Steiniger has also been supported by the Centro de Desarrollo Urbano Sustentable (CEDEUS), Conicyt/Fondap/1511 0020, and the project "AccesoBarrio" (Fondecyt 1150239).

\section{Conflict of Interests}

The authors declare no conflict of interests.

\section{References}

Allen, M., Regenbrecht, H., \& Abbott, M. (2011). Smartphone augmented reality for public participation in urban planning. Proceedings of the 23rd Australian computer-human interaction conference (pp. 11-20). Canberra, AU: Association for Computing Machinery.

Alvarado, C., \& Davis, R. (2004). SketchREAD: A multidomain sketch recognition engine. Proceedings of the 17th annual ACM symposium on user interface software and technology (pp. 23-32). Santa Fe, NM, USA: Association for Computing Machinery.

Arnstein, S. R. (1969). A ladder of citizen participation. Journal of the American Institute of Planners, 35(4), 216-224.

Bang, H., \& Esmark, A. (2009). Good governance in network society: Reconfiguring the political from politics to policy. Administrative Theory \& Praxis, 31(1), 7-37.

Barton, J. E., Goldie, X. H., \& Pettit, C. J. (2015). Introducing a usability framework to support urban information discovery and analytics. Journal of Spatial Science, 60(2), 1-17.

Bliss-Taylor, C. A. M. (2014). Design of a support tool for citizens engaging in urban planning online (MSc thesis). University of Calgary, Calgary.

Bohøj, M., Borchorst, N. G., Bødker, S., Korn, M., \& Zan- 
der, P. O. (2011). Public deliberation in municipal planning: Supporting action and reflection with mobile technology. Proceedings of the 5th international conference on communities and technologies (pp. 8897). Brisbane, AU: Association for Computing Machinery.

Bugs, G., Granell, C., Fonts, O., Huerta, J., \& Painho, M. (2010). An assessment of public participation GIS and Web 2.0 technologies in urban planning practice in Canela, Brazil. Cities, 27(3), 172-181.

Butt, M. A., \& Li, S. (2012). Developing a web-based, collaborative PPGIS prototype to support public participation. Applied Geomatics, 4(3), 197-215.

Carver, S., Evans, A., Kingston, R., \& Turton, I. (2001). Public participation, GIS, and cyberdemocracy: Evaluating on-line spatial decision support systems. Environment and Planning $B, 28(6), 907-922$.

Cinderby, S. (2010). How to reach the "hard-to-reach": The development of participatory geographic information systems (P-GIS) for inclusive urban design in UK cities. Area, 42(2), 239-251.

Cohen, D., Lindvall, M., \& Costa, P. (2004). An introduction to agile methods. Advances in Computers, 62, 166.

Coleman, S., \& Moss, G. (2012). Under construction: The field of online deliberation research. Journal of Information Technology \& Politics, 9(1), 1-15.

Costello, C. (2012). Elgg 1.8 social networking: Create, customize, and deploy your very own social networking site with Elgg. Birmingham, UK: Packt Publishing.

Diehl, J. (2011, October 27). Fahndung bei Facebook: Der Polizei gefällt das. SPIEGEL ONLINE. Retrieved from http://www.spiegel.de/panorama/gesellschaft/0,151 8,793974,00.html

Donders, M., Hartmann, T., \& Kokx, A. (2014). Eparticipation in urban planning: Getting and keeping citizens involved: International Journal of E-planning Research, 3(2), 54-69.

Drummond, W. J., \& French, S. P. (2008). The future of GIS in planning: Converging technologies and diverging interests. Journal of the American Planning Association, 74(2), 161-174.

Ellison, N. B., Steinfield, C., \& Lampe, C. (2007). The benefits of Facebook "friends": Social capital and college students' use of online social network sites. Journal of Computer-Mediated Communication, 12(4), 11431168.

Evans-Cowley, J. (2012). There's an app for that. International Journal of E-planning Research, 1(2), 79-87.

Evans-Cowley, J., \& Hollander, J. (2010). The new generation of public participation: Internet-based participation tools. Planning Practice and Research, 25(3), 397-408.

Evans-Cowley, J. S. (2010). Planning in the age of Facebook: The role of social networking in planning processes. GeoJournal, 75(5), 407-420.

Foth, M., Klaebe, H. G., \& Hearn, G. N. (2008). The role of new media and digital narratives in urban planning and community Development. Body, Space \& Technology, 7(2). Retrieved from http://eprints.qut.edu. au/13148/

Granell, C., Díaz, L., \& Gould, M. (2010). Service-oriented applications for environmental models: Reusable geospatial services. Environmental Modelling \& Software, 25(2), 182-198.

GSDI. (2009). Spatial data infrastructure cookbook. Global Spatial Data Infrastructure Association. Retrieved from http://memberservices.gsdi.org/files/? artifact_id=655

Guhathakurta, S. (1999). Urban modeling and contemporary planning theory: Is there a common ground? Journal of Planning Education and Research, 18(4), 281-292.

Gutmann, M. P., \& Stern, P. C. (2007). Putting people on the map: Protecting confidentiality with linked socialspatial data. Washington D.C.: The National Academic Press.

Haklay, M., \& Tobón, C. (2003). Usability evaluation and PPGIS: Towards a user-centred design approach. International Journal of Geographical Information Science, 17(6), 577-592.

Hall, G. B., Chipeniuk, R., Feick, R. D., Leahy, M. G., \& Deparday, V. (2010). Community-based production of geographic information using open source software and Web 2.0. International Journal of Geographical Information Science, 24(5), 761-781.

Haworth, B., \& Bruce, E. (2015). A review of volunteered geographic information for disaster management. Geography Compass, 9(5), 237-250.

Horose, C. (2014, September 2). Let's get digital! 50 Tools for online public engagement. CommunityMatters. Retrieved from http://www.communitymatters. org/blog/let\%E2\%80\%99s-get-digital-50-tools-online -public-engagement

Hunter, A. J. S., Steiniger, S., Sandalack, B. A., Liang, S. H. L., Kattan, L., Shalaby, A. S., . . Martinson, R. (2012). PlanYourPlace: A geospatial infrastructure for sustainable community planning. Revue Internationale de Géomatique, 22(2), 223-253.

Hunter, A., Sandalack, B. A., Liang, S., Kattan, L., \& Shalaby, A. (2011). PlanYourPlace: Workshop 1 Report: project planning and priorities. Calgary, Canada: PlanYourPlace.ca.

International Association for Public Participation. (n.d.). Foundations of public participation. International Association for Public Participation. Retrieved from http://www.iap2.org.au/documents/item/83

Jankowski, P., Robischon, S., Nyerges, T., Ramsey, K., \& Tuthill, D. (2006). Design considerations and evaluation of a collaborative, spatio-temporal decision support system. Transactions in GIS, 10(3), 335-354.

Kakabadse, A., Kakabadse, N. K., \& Kouzmin, A. (2003). Reinventing the democratic governance project through information technology? A growing agenda 
for debate. Public Administration Review, 63(1), 4460.

King, R. (2015, January 20). Google maps engine could be quietly coming to a halt soon. ZDNet. Retrieved from http://www.zdnet.com/article/google-mapsengine-quietly-coming-to-a-halt-as-sign-up-windowshutters/

Kingston, R., Carver, S., Evans, A., \& Turton, I. (2000). Web-based public participation geographical information systems: an aid to local environmental decision-making. Computers, Environment and Urban Systems, 24(2), 109-125.

Laanti, M., Salo, O., \& Abrahamsson, P. (2011). Agile methods rapidly replacing traditional methods at Nokia: A survey of opinions on agile transformation. Information and Software Technology, 53(3), 276290.

Lennertz, B., Lutzenhiser, A., \& Failor, T. (2008). An introduction to charrettes. Planning Commissioners Journal, 71, 1-3.

Lüscher, P., Weibel, R., \& Burghardt, D. (2009). Integrating ontological modelling and Bayesian inference for pattern classification in topographic vector data. Computers, Environment and Urban Systems, 33(5), 363-374.

Mandarano, L., Meenar, M., \& Steins, C. (2010). Building social capital in the digital age of civic engagement. Journal of Planning Literature, 25(2), 123-135.

McAfee, A. P. (2006). Enterprise 2.0: The dawn of emergent collaboration. MIT Sloan Management Review, 47(3), 21-28.

Newman, G., Zimmerman, D., Crall, A., Laituri, M., Graham, J., \& Stapel, L. (2010). User-friendly web mapping: Lessons from a citizen science website. International Journal of Geographical Information Science, 24(12), 1851-1869.

Nielsen, J. (1993). Usability engineering. San Francisco, CA: Morgan Kaufmann.

Nivala, A.-M., Brewster, S., \& Sarjakoski, L. T. (2008). Usability evaluation of web mapping sites. The Cartographic Journal, 45(2), 129-138.

Oksman, V., Väätänen, A., \& Ylikauppila, M. (2014). Future illustrative and participative urban planning. CONTENT 2014, the sixth international conference on creative content technologies (pp. 22-29). Venice, ItaIy: IARIA. Retrieved from http://www.thinkmind.org/ index.php?view=article\&articleid=content_2014_2_1 0_60052

Peng, Z. R. (2001). Internet GIS for public participation. Environment and Planning B, 28(6), 889-906.

Percivall, G. (2010). Progress in OGC web services interoperability development. In L. Di \& H. K. Ramapriyan (Eds.), Standard-based data and information systems for earth observation (pp. 37-61). Berlin, Germany: Springer.

Pettit, C. J., Klosterman, R. E., Nino-Ruiz, M., Widjaja, I., Russo, P., Tomko, M., . . . Stimson, R. (2013). The online what if? Planning support system. In S. Geertman, F. Toppen, \& J. Stillwell (Eds.), Planning support systems for sustainable urban development (pp. 349-362). Berlin, Germany: Springer.

Pettit, C. J., Raymond, C. M., Bryan, B. A., \& Lewis, H. (2011). Identifying strengths and weaknesses of landscape visualization for effective communication of future alternatives. Landscape and Urban Planning, 100(3), 231-241.

Pettit, C., Widjaja, I., Russo, P., Sinnott, R., Stimson, R., \& Tomko, M. (2012). Visualization support for exploring urban space and place. Proceedings of XXII ISPRS congress, technical commission IV (pp. 153-158). Melbourne, AU: ISPRS International Archives of Photogrammetry, Remote Sensing, and Spatial Information Science. Retrieved from http://minervaaccess.unimelb.edu.au/handle/11343/32705

Pew Research Center. (2011). Global digital communication: Texting, social networking popular worldwide. Washington, DC: Pew Research Center. Retrieved from http://www.pewglobal.org/2011/12/20/globaldigital-communication-texting-social-networkingpopular-worldwide/?src=prc-number

Poorazizi, M. E., Steiniger, S., \& Hunter, A. J. S. (2015). A service oriented architecture to enable participatory planning: An e-planning platform. International Journal of Geographical Information Science, 29(7), 10811110.

Poplin, A. (2012). Playful public participation in urban planning: A case study for online serious games. Computers, Environment and Urban Systems, 36(3), 195-206.

Rajabifard, A., \& Williamson, I. P. (2001). Spatial data infrastructures: Concept, SDI hierarchy and future directions. Proceedings of Geomatics '80. Tehran, Iran, Retrieved from http://minerva-access.unimelb.edu. au/handle/11343/33897.

Reid, A., \& Petocz, P. (2006). University lecturers' understanding of sustainability. Higher Education, 51(1), 105-123.

Reid, A., Petocz, P., \& Taylor, P. (2009). Business students' conceptions of sustainability. Sustainability, 1(3), 662-673.

Riggs, B., Chavan, A., \& Steins, C. (2015, January 27). City planning department technology benchmarking survey 2015. Planetizen. Retrieved from http://www.pla netizen.com/node/73480/city-planning-departmenttechnology-benchmarking-survey-2015

Rinner, C., \& Bird, M. (2009). Evaluating community engagement through argumentation maps-a public participation GIS case study. Environment and Planning $B, 36(4), 588-601$.

Rinner, C., Keßler, C., \& Andrulis, S. (2008). The use of Web 2.0 concepts to support deliberation in spatial decision-making. Computers, Environment and Urban Systems, 32(5), 386-395.

Roth, R. E., \& Harrower, M. (2008). Addressing map in- 
terface usability: Learning from the Lakeshore nature preserve interactive map. Cartographic Perspectives, 60(Spring), 4-24.

Rubin, J., \& Chisnell, D. (2008). Handbook of usability testing: How to plan, design and conduct effective tests Indianapolis, IN: Wiley.

Rykiel, E. J. (1996). Testing ecological models: The meaning of validation. Ecological Modelling, 90(3), 229244.

Sandars, J., \& Lafferty, N. (2010). Twelve tips on usability testing to develop effective e-learning in medical education. Medical Teacher, 32(12), 956-960.

Sani, A., \& Rinner, C. (2011). A scalable geoweb tool for argumentation mapping. Geomatica, 65(2), 145-156.

Schut, P. (2007, June 8). OpenGIS web processing service. The Open Geospatial Consortium. Retrieved from portal.opengeospatial.org/files/?artifact_id $=28$ $772 \&$ version $=2$

Schwaber, K., \& Sutherland, J. (2011). The SCRUM guide. SCRUM. Retrieved from scrum.org

Schwilch, G., Bachmann, F., \& de Graaff, J. (2012). Decision support for selecting SLM technologies with stakeholders. Applied Geography, 34, 86-98.

Seltzer, E., \& Mahmoudi, D. (2013). Citizen participation, open innovation, and crowdsourcing challenges and opportunities for planning. Journal of Planning Literature, 28(1), 3-18.

Sheppard, S. R. J., \& Cizek, P. (2009). The ethics of Google Earth: Crossing thresholds from spatial data to landscape visualisation. Journal of Environmental Management, 90(6), 2102-2117.

Sinnott, R. O., Bayliss, C., Bromage, A., Galang, G., Grazioli, G., Greenwood, P., . . . Widjaja, I. (2015). The Australia urban research gateway. Concurrency and Computation: Practice and Experience, 27(2), 358375.

Smyth, E. (2001). Would the Internet widen public participation? (MRes Thesis). University of Leeds, UK.

Staffans, A., Rantanen, H., \& Nummi, P. (2010). Online environments shake up urban planning: Developing local internet forums. In S. Wallin, L. Horelli, \& J. Saad-Sulonen (Eds.), Digital tools in participatory planning (p. 37). Espoo, Finland: Aalto University.

Steiniger, S., \& Bocher, E. (2009). An overview on current free and open source desktop GIS developments. International Journal of Geographical Information Science, 23(10), 1345-1370.

Steiniger, S., \& Hunter, A. J. S. (2013). The 2012 free and open source GIS software map: A guide to facilitate research, development and adoption. Computers, Environment and Urban Systems, 39(1), 136-150.

Steiniger, S., Poorazizi, M. E., Bliss-Taylor, C. A. M., Mo- hammadi, E., \& Hunter, A. J. S. (2012). PlanYourPlace: Merging social networks and participatory GIS for participatory planning. FIG Working Week 2012. Rome, Italy: FIG: International Federation of Surveyors.

Steiniger, S., Poorazizi, M. E., \& Hunter, A. J. S. (2013). WalkYourPlace: Evaluating neighbourhood accessibility at street level. In C. Ellul, S. Zlatanova, M. Rumor, \& R. Laurini (Eds.), Proceedings of the 29th urban data management symposium (Vol. XL-4/W1). London, UK: ISPRS International Archives of Photogrammetry, Remote Sensing, and Spatial Information Science.

Talen, E. (2000). Bottom-up GIS. Journal of the American Planning Association, 66(3), 279-294.

Tippett, J., Handley, J. F., \& Ravetz, J. (2007). Meeting the challenges of sustainable development: A conceptual appraisal of a new methodology for participatory ecological planning. Progress in Planning, 67(1), 9-98.

Tomko, M., Greenwood, P., Sarwar, M., Morandini, L., Stimson, R., Bayliss, C., . . Sinnott, R. (2012). The design of a flexible web-based analytical platform for urban research. Proceedings of the 20th international conference on advances in geographic information systems (pp. 369-375). New York: Association for Computing Machinery.

VecinosConectados. (n.d.). Homepage. VecinosConectados. Retrieved from http://vecinosconectados.cl

Voss, A., Denisovich, I., Gatalsky, P., Gavouchidis, K., Klotz, A., Roeder, S., \& Voss, H. (2004). Evolution of a participatory GIS. Computers, Environment and Urban Systems, 28(6), 635-651.

Wu, H., He, Z., \& Gong, J. (2010). A virtual globe-based $3 \mathrm{D}$ visualization and interactive framework for public participation in urban planning processes. Computers, Environment and Urban Systems, 34(4), 291-298.

Yin, P., Chang, M. D., \& Forbus, K. D. (2010). Sketchbased spatial reasoning in geologic interpretation. Proceedings of the 24th International Workshop on Qualitative Reasoning. Portland, OR: Cognitive Science Society. Retrieved from http://www.qrg.north western.edu/papers/Files/QRG_Dist_Files/QRG_201 0/QR2010_Yin_Final.pdf

Zhao, J., \& Coleman, D. J. (2006). GeoDF: Towards a SDIbased PPGIS application for e-governance. Proceedings of the GSDI 2006 (Vol. 9). Santiago de Chile, Chile: Global Spatial Data Infrastructure Association.

Zhao, P., Yu, G., \& Di, L. (2007). Geospatial web services. In B. N. Hilton (Ed.), Emerging spatial information systems and applications (pp. 1-35). Hershey, PA: Idea Group Publishing. 


\section{About the Authors}

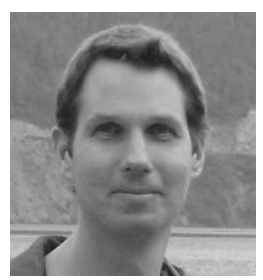

Stefan Steiniger (PhD) is currently in charge of the spatial data infrastructure/observatory of the Centre for Urban Sustainable Development (CEDEUS) in Santiago de Chile. With a background in automated map generalization he has a wide interest in free \& open source GIS tools and their applications in diverse fields including cartography, wildlife ecology, landscape ecology, and transportation. His latest research focuses on developing tools for e-participation in planning and exploring new data sources to inform urban planning.

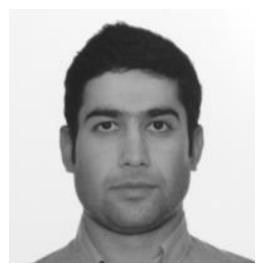

M. Ebrahim Poorazizi is a PhD student in Geomatics Engineering at the University of Calgary, Canada, and a geospatial solutions architect and software developer. His research focuses on the development of service-based spatial data architectures for use in e-planning and disaster management. Currently he develops models and tools to utilize VGI (Volunteered Geographic Information) as a complementary source of information together with governmental databases to enable real-time geospatial modeling and emergency response.

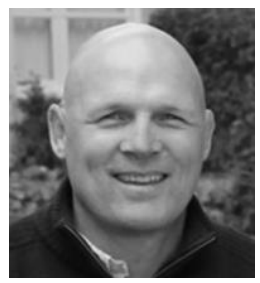

Andrew J. S. Hunter (PhD, P.Eng., RPSurv.) is now a Senior Surveying Engineer at McKenzie \& Co, in Auckland, and was, until moving in 2014 to New Zealand, an Associate Professor for Land Tenure at the University of Calgary, Canada. His teaching and research interests involve participation in planning, land use planning, land development, surveying and GIS. He also developed a GPS-based collar that is used to track grizzly bear movements in the Rocky Mountains for ecological research. 